\title{
Visual Interpretation
}

National Cancer Institute

\section{Source}

National Cancer Institute. Visual Interpretation. NCI Thesaurus. Code C95000.

Perusal of an image for information that can be gleaned from the relative intensities that display tracer uptake. 